\title{
Influencia de las adiciones, inertes o activas, en las propiedades de los cementos
}

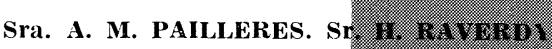

Laboratorio Central de Puentes y Gaminos. N.o 96. phis. $4 \% .1070$

Con motivo de una probable normalización de cementos portland con adiciones de finos silícicos, puzolanas y cenizas volantes hasta un $35 \%$, el Laboratorio Central de Puentes y Caminos realizó un estudio para poner de manifiesto, en forma cuantitativạ, la influencia de las diversas adiciones sobre las características, normalizadas o no, de los cementos resultantes.

El estudio se llevó a cabo sobre 78 cementos compuestos a partir de PA con adiciones del $10-20-35 \%$ de finos.

\section{Ensayos físicos}

Granulometría. Variación de volumen, retracción, fisurabilidad y fraguado.

\section{Ensayos mecánicos}

Resistencias a la compresión a 28-90 y 365 días.

Los ensayos se realizaron en dos series, una con los cementos obtenidos por la mezcla de cementos PA y las adiciones; la otra por la molturación conjunta del clínker de portland con las diversas adiciones.

\section{Resultados}

La introducción de cantidades variables de finos, incluso activos, parece tener una influencia relativamente benéfica sobre ciertas características de los morteros: retracción, fisuración, variación de volumen; los fraguados se retardan algo pero sin efectos graves a. $20^{\circ} \mathrm{C}$.

Todo pasa como si las adiciones no tuvieran otra influencia que la de "finos de arena"; al disminuir la cantidad de cemento en el mortero disminuye la fisuración y la variación de volumen.

Las resistencias disminuyen en función de la dosificación de finos añadidos. Para el $10 \%$ los resultados no son muy bajos, con el 20 y el $35 \%$ las resistencias son más débiles. 
La incorporación de puzolana, hasta los 90 días, modifica poco las resistencias; las cenizas volantes presentan disminuciones más débiles con tendencia a mejorar; al año los cementos que las contenían llegaron a superar las resistencias de los testigos en más dei 20 y $30 \%$.

El Director General del CERILH, Sr. J. P. Meric comentó, extensa y laudatoriamente, el trabajo realizado y, en su comentario, indicó que los trabajos en curso, del CERILH desde algunos años, coinciden con los del Laboratorio de P. y C. y, además, han puesto de manifiesto que la composición granulométrica de las fracciones más finas de un hormigón (clínker, finos, puzolanas, escorias) determinan las cualidades del mismo. Parece como si los finos no pudieran ejercer totalmente su influencia si poseen la misma granulometría que el clínker, es decir, los granos de finos deben ocupar los espacios intersticiales entre los granos de clínker.

Entonces se puede escoger, para el clínker, la granulometría más eficaz desde el punto de vista de la cinética de la hidratación, y para los finos, una curva granulométrica complementaria con lo cual los finos actuarían positivamente a pesar de su inercia química.

Los cementos, con adiciones inertes así compuestos, no siguen la ley de Feret y presentan en todos los casos resistencias muy superiores a las previstas por dicha ley.

P. G. de P. (IETCC) 